of the principle to the effects of varying the exposure time, the emissions as well as the absorptions may be examined; in this way the three-stage absorption product is found to develop rendily only when accompanied by one intermediate emission-unless this emission occurs, the product is a so-called ' reversed' grain.

It may be noted that while grain counts of fully blackened grains refer to both the two stage and the three or more stage absorption images, counts of grains containing one or more 'nuclei' after partial dovolopment refer to the three or more stage absorption product only.

These results, if accepted, would place the photographic action among the phenomena of phosphorescence.

Royal Observatory, Edinburgh, Nov. 22.

\section{Misleading Uses of the Term 'Self-Adaptation.'}

MAY I be permitted to direct attention to the use of loose terminology that occurs all too frequently even in some important scientific articles? The particular term that $I$ refer to is that in which plants and animals are said to have adapted thernselves to some particular environment, etc.

Thus in an article in NATURE of Nov. $26, \mathrm{p} .786$, giving the substance of a paper read by Dr. C. M. Wenyon to the Royal Society of Edinburgh, flagellates are said to have adapled themselves to life, otc., and this expression is used in the article no less than three times.

Such expressions as animals adapting themselves, and shade-loving plants, etc., and even the term mimicry, are highly undesirable, though the last term is far ton well established for any protest to be effective now. The reason why thoy are undesirable is that they savour of anthropomorphism; and in these days when one hears so much about natural selection from all quarters, it is imperative to guard scientific terminology most carefully.

These expressions, of course, do not cause any misconception in the mind of the trained scientist, but they are too frequently copied in text-books, elementary and otherwise, and there do a great deal of harm by giving the young student and the lay reader a totally wrong impression. Again, it becomes a very difficult task for the teacher to discourage the use of expressions of this kind amongst his pupils when they are used by leading authorities.

Such is the desire of the everyday citizen for scientific knowledge at the present time, that no scientific writer is free from the possibility of having his articles appear in a popular form in general literaturo; the responsibility for accuracy on his part is therefore great.

Marlborough College, Wilts.

\section{Regularities in the Spark Spectrum of Silver.}

AcCorDIng to the theory of Hund, the fundamental terms of the spark spectrum of silver would consist of a deep ${ }^{1} S_{0}$-term (combination $d^{10}$ ) with metastablo triplet and singlet $D$-torms $\left(d^{9} s^{1}\right)$. These would combine with $a$ set of triplet and singlet $F, D$, and $P$. terms $\left(d^{9} p^{\mathbf{1}}\right)$.

I have been able to identify tho fundamental triplet and singlet $D$-terms, and the second set of terms. Higher Rydberg sequence to the fundamental $D$-terms has also been obtained. It has thus been possible to calculate the approximate value of the metastable $D$-terms. The deepest ${ }^{3} D_{3}$-term has a value of about 138,000 , corresponding to an ionisation potential of 17 volts, the consecutive differences being $1577\left({ }^{3} D_{3}{ }^{3} D_{2}\right), 2999\left({ }^{3} D_{2^{-}}{ }^{3} D_{1}\right)$, and $2306\left({ }^{3} D_{1}-1 D_{1}\right)$.

The arc spectrum of silver is a purely doublet spectrum, the metastable inverted $D$-terms which are such prominent features of the analogous metals copper and gold being either totally absent or failing to occur under the usual conditions of excitement. The fundamental ${ }^{1} S_{0}$ will have thus a much higher value than ${ }^{3} D_{3}$. For $\mathrm{Cu}^{+}$the corresponding value has been calculated by shenstone to be 22,224 . Taking the corresponding value for silver to be 40,000 , the ionisation potential of $\mathrm{Ag}^{+}$comes out to be about 22 volts, subject to the approximate nature of the assumptions made in the calculation.

\section{K, Majumdar.}

Physies Department,

Allahabad University, Allahabad, India,

$$
\text { Nov. } 3 .
$$

\section{Solution of the Equation $\sin \theta / \theta=c$.}

Major A. E. Levin (Nature, Nov. 26) points out that the usual solution of the above equation by the method of successive approximations is more simple than that which I gave in NATURE of Oct. 1. 'The exprossion which $I$ gave is only intended as a first approximation, and as such should only be compared, if comparison is necessary, with the first approximation ${ }_{1} \theta_{a}=\sqrt{ } 6 \bar{d}=\sqrt{6(1-c)}$, in the method he indicates.

If such comparison be made when $1 / c=K=1.072502$ and $K=1.5707963$, my expression gives errors $+5^{\prime} 32^{\prime \prime}$ and $+1^{\circ} 6^{\prime} 49^{\prime \prime}$, whilst $\theta_{a}$ gives orrors $-22^{\prime} 48^{\prime \prime}$ and $-5^{\circ} 23^{\prime} 54^{\prime \prime}$, the true solutions being $36^{\circ} 52^{\prime} 12^{\prime \prime}$ and $90^{\circ}$.

It will bo seen that over this range the relative error resulting from the use of my expression is about one-fifth of that with the expression $\theta_{a}$. This meets that part of Major Levin's letter that refers to my original remarks, which I confined to the range $0^{\circ}$ to $5^{\circ}$.

There are, however, other advantages that make my expression worth consideration as a first approximation. Thus, if $c=0 \cdot 1909860$ and $d=0 \cdot 8090140$, $\mathrm{my}$ expression gives the answer with an error $+2^{\circ} 17^{\prime} 49^{\prime \prime}$, an error that can be removed by a further stage of approximation, the true answer being $150^{\circ}$.

IT.M. Dockyard School,

V. NAYLOR.

Devonport.

Calendar of Discovery and Invention.

IN this week's issue appears the last group of notes of the Calendar of Discovery and Invention which I have had the ploasure of eontributing to NA'TURE during the past year. This calendar has aimed at recalling somo of the most important advances in science and some of the principal mechanical inventions, and is supplementary to the Calendars of Scientific and Industrial Pioneors which appeared in 1921 and 1922. In the preparation of these notes I have received assistance from many sources, and I should like to take this opportunity of thanking Dr. W. Clark, Mr. A. Gomme, Mr. B. $\Lambda$. Behrend, Dr. R. T. Gunther, and Sir Charles Sherrington for thoir kindness in placing information at my disposal. The late Dr. Daydon Jackson also kindly sent several interesting notes, which were included in the Calendar, referring to botany and the Linnean Society.

Riddleswood, Seloroft Road, Purley, Surrey.

No. 3034, VoL. 120] 